\title{
Uma Análise Conceitual da Dignidade cOMO Fundamento dos Direitos Humanos E SUA INVOCAÇÃO EM DECISÕES DO STF E DA CIDH
}

\author{
Rafael Seixas Santos* \\ Marcelo Dias Varella**
}

1 Introdução. 2 A dignidade como um fundamento dos direitos humanos. 2.1 A dignidade funda o reconhecimento dos Direitos Humanos do semelhante. 2.2 A diversidade dos meios e discursos de invocação da dignidade como fundamento dos direitos humanos. 2.3 A fragilidade da dignidade como único fundamento. 3 A defesa dos Direitos Humanos por meio da dignidade em decisões do STF e da CIDH. 3.1 Da força da construção jurisprudencial, ou do porquê de se analisar o arcabouço das decisões judiciais. $3.2 \mathrm{O}$ discurso jurisprudencial na tentativa de formatar um conceito operacional de dignidade: julgados distintos com fundamentação abrangente. 4 Considerações finais. Referências.

\section{RESUMO}

O princípio da dignidade da pessoa humana tem funcionado como fundamento dos Direitos Humanos de modo recorrente em Instituições de relevo nas sociedades democráticas, a exemplo do Supremo Tribunal Federal (STF), no Brasil, e da Corte Interamericana de Direitos Humanos (CIDH). Avaliar como a dignidade pode justificar a aplicação dos Direitos Humanos, inclusive apresentando algumas decisões dessas Cortes, como propõe este texto, contribui para tecer uma fundamentação abrangente a fim de reforçar o emprego da expressão nas diversas esferas sociais. Assim, por meio de uma construção teórica do conceito operacional "dignidade fundamentando Direitos Humanos" e da verificação de seu posicionamento em algumas decisões desses Tribunais, verifica-se a validade e a eficácia do emprego do fundamento. Ainda há amplo campo fértil para o aperfeiçoamento conceitual e para a definição de paradigmas de emprego do fundamento.

Palavras-chave: Dignidade. Fundamento. Direitos Humanos. STF. CIDH.

* Professor do Instituto de Educação Superior de Brasília (IESB). Discente vinculado ao Programa de Mestrado do Centro Universitário de Brasília (UniCEUB). E-mail: <rafaelseixas. email@gmail.com>.

** Doutor em Direito pela Universidade de Paris, Panthéon-Sorbonne (2002). Livre-docente em Direito Internacional pela Faculdade de Direito da Universidade de São Paulo (2013). Pós-Doutorado em Direito nas Universidades da California, em Berkeley; George Washington; e Georgetown (2011 e 2012). Professor do Programa de Mestrado e Doutorado em Direito do Centro Universitário de Brasília.E-mail: <marcelodvarella@gmail.com>. 


\section{INTRODUÇÃO}

A importância que o conceito de dignidade da pessoa humana vem assumindo na seara dos preceitos políticos, filosóficos e jurídicos que justificam a defesa das pessoas em face do Estado ou dos outros indivíduos tem posicionado o princípio como um dos fundamentos dos Direitos Humanos. A construção dessa estrutura, que funda os Direitos Humanos em macroprincípios ou valores, como a dignidade, tem sido realizada de modo declarado ou incidental, por Instituições de relevo nas arenas nacionais das diversas sociedades democráticas, a exemplo das Cortes Constitucionais.

A proposta deste texto é avaliar como a dignidade pode fundamentar a aplicação dos Direitos Humanos, especialmente na atividade do Supremo Tribunal Federal e, em nível comparativo, no âmbito da Corte Interamericana de Direitos Humanos. Por meio da análise de conceitos e considerações amplas, formuladas por diversos autores, será construída uma plataforma conceitual homogênea que elucide, em linhas gerais, como ocorre a fundamentação dos Direitos Humanos pela dignidade. Em seguida, será testada a aplicação prática da dignidade como fundamento. $O$ teste se dará por meio da apresentação de alguns casos em que ocorreu o uso da dignidade pelo STF e pela CIDH para fundamentar a tutela de Direitos Humanos. ${ }^{1}$

A dignidade é um dos conceitos mais reiteradamente empregados em todo o Direito Constitucional e em Direitos Humanos. No Brasil, a Constituição Federal de 1988 prevê, no artigo $1^{\circ}$, inciso III, a dignidade da pessoa humana como fundamento axiológico da República e insere a dignidade como fundamento de direitos notadamente humanos em, pelo menos, outras três articulações, como nos artigos $226, \S 7^{\circ} ; 2227^{3}$ e $230^{4}$. E de se notar que o princípio se encontra previsto, também, nas Constituições de Portugal (art. $\left.1^{\circ}\right)$, da Espanha (art. 10), da Itália (art. 41), dentre diversas outras.

Quando põe a dignidade da pessoa humana na posição de fundamento dos Direitos Humanos integrantes do Estado Democrático de Direito, a Constituição Federal brasileira reconhece que é o Estado que existe em função dos seres humanos, e não o contrário, uma vez que o bem-estar do ser humano constitui a finalidade precípua, e não um meio da atividade estatal. ${ }^{5} \mathrm{E}$ mais, a teoria crítica dos Direitos Humanos urge por uma nova perspectiva, com base em práticas sociais emancipatórias, sob a visão de que os Direitos Humanos são resultados provisórios, e em construção, de lutas sociais por dignidade. ${ }^{6}$

Como um preceito Constitucional, o princípio da dignidade (enquanto componente fundamental dos Direitos Humanos) está em recorrente verte no Supremo Tribunal Federal. De fato, no Brasil, o STF ocupa destacada posição no campo da definição e do emprego da dignidade como fundamento para os Direitos Humanos, especialmente pela importância e relevância constitucional, social e política conferida a essa Corte e às suas Decisões. Por isso, é importante apresentar o modo como essa Corte Constitucional recorre ao fundamento da 
dignidade na defesa dos Direitos Humanos e como as suas Decisões são consentâneas (ou não) com as Decisões da CIDH.

Todavia, como se verá no decorrer do texto, a Suprema Corte tem se valido do argumento da dignidade como fundamento de Direitos Humanos não somente em casos relevantes do ponto de vista da abstração conceitual, mas também em passagens ordinárias. ${ }^{7}$ De igual modo, o Tribunal tem empregado o conceito operacional ${ }^{8}$ com tão amplo espectro de alcance que, em incontáveis episódios, se pode verificar sua invocação - o que representa uma banalização do instituto. Com efeito, isso não representa algo necessariamente ruim para o universo dos Direitos Humanos, como se revelará adiante. Tais limites são definidos em razão do desenvolvimento histórico-cultural da sociedade e de seus valores. ${ }^{9}$

Como já anotado, o emprego exacerbado do princípio da dignidade como fundamento de Direitos Humanos conduz a sua efemerização. É recomendável certa cautela, por parte do STF (e de seus membros) e da CIDH, no emprego da expressão como fundamento das suas Decisões, especialmente em razão da grave missão que lhes é confiada na Carta Política e nas normas internacionais. É preciso atenção ao emprego do princípio da dignidade da pessoa humana, pois os excessos de aplicações inflacionadas podem ensejar seu esvaziamento material e eficacial, e uma postura mais harmônica ou padronizada parece ser uma alternativa para não se cair em um vazio conceitual.

Portanto, o texto objetiva validar o emprego da dignidade como fundamento para aplicação dos Direitos Humanos por meio da exploração de conceitos gerais e da apresentação de alguns casos em que ocorre a invocação do conceito operacional nas Decisões do STF e da CIDH.

\section{A DIGNIDADE COMO UM FUNDAMENTO DOS DIREITOS HUMANOS}

Um dos campos de mais acidentado relevo na esfera da dignidade humana é o da sua conceituação e assimilação como fundamento para os Direitos Humanos. Em razão disso, é necessário adotar um sentido prático, um conceito abrangente e viável, a fim de se amalgamar e comparar com aquele que o STF e a CIDH têm construído.

Ao se verificar a dignidade enquanto princípio e escopo de interpretação, é preciso imaginar um sujeito dotado de valor intrínseco, que conta com garantias (e com Direitos Humanos) e que deve ser encarado como um fim em si mesmo, em que pesem as consequências que suas ações (ou omissões) possam trazer à sociedade de que faz parte, dado que a dignidade humana condecora um ser racional, que carrega um fim em si mesmo. ${ }^{10}$

De início, não há como olvidar da ideia kantiana, segundo a qual a dignidade diferencia o ser racional dos demais e, ao lhe conferir autonomia, 
torna o indivíduo capaz de se autodeterminar. ${ }^{11} \mathrm{~A}$ autonomia é, assim, um dos elementos caracterizadores da dignidade. Tal autonomia somente encontra pleno exercício quando seu titular dispõe de liberdade, de modo que o próprio Estado tenha a obrigação negativa (de não interferir no campo das liberdades humanas básicas, exceto nos casos de violações inter-humanas) e desde que os cidadãos semelhantes reconheçam e respeitem a liberdade individual. Em outras palavras, dignidade pressupõe igualdade.

É que o universo dos Direitos Humanos é transdisciplinar e goza de atributos especiais: a universalidade e a indivisibilidade. ${ }^{12}$ Isso decorre da miríade de os direitos civis, políticos, econômicos, sociais e culturais serem resultantes da soma do valor da liberdade com o valor da igualdade; e o cenário se torna mais complexo à medida que o movimento da internacionalização do Direito se intensifica e por ele passam as torrentes de mecanismos e meios de promoção de Direitos Humanos pela desconstrução individualista de valores. Valores individuais passam a sobressair em face de valores coletivos. ${ }^{13}$

Sob o aspecto jurídico e político-constitucional, uma pessoa que decide praticar comportamentos que sejam protegidos pela reserva de intimidade da vida privada em local público, por exemplo, não está, em virtude desse comportamento, renunciando seu direito, mas sim o exercendo conforme suas próprias preferências e concepções. ${ }^{14}$

Assim, dada a inserção social dos agentes detentores de Direitos Humanos, associada às liberdades civis, políticas, econômicas e diversas outras, o campo de aplicação desses direitos permeia a realidade política que seus portadores e que os próprios direitos integram. Desse modo, verifica-se que a dignidade, ao supedanear Direitos Humanos, não prevê a necessária adoção de um meio específico de vida ou de existência.

\subsection{A DIGNIDADE FUNDA O RECONHECIMENTO DOS DIREITOS HUMANOS DO SEMELHANTE}

Somente por meio da apreensão de que o desenvolvimento do direito do semelhante é gerado pela existência de dignidade no outro é que se podem fundar Direitos Humanos que são, por sua natureza, intrínsecos, mas de reconhecimento exterior.

As arenas que empregam o fundamento da dignidade em suas decisões - sobretudo as Cortes Constitucionais - devem ter em verte, na construção de seus conceitos jurídicos, a ideia de dignidade como igualdade e, por isso, decorrente do reconhecimento do indivíduo pelos semelhantes, o que acaba por tornar o instituto um conceito político, mas que, ao mesmo tempo, deve ser abrangente o suficiente para fundamentar os Direitos Humanos. Curioso é como tal percepção se amolda ao liberalismo político que dispõe caber aos cidadãos o estabelecimento da forma de relacionamento de valores de domínio político com outros valores de sua doutrina abrangente. ${ }^{15}$ 
Portanto, a dignidade, como princípio-âncora dos Direitos Humanos, deve repousar em uma visão política e abrangente, para que se construa uma conceituação plana e homogênea sob o aspecto do alcance e da durabilidade, e não como algo meramente utilitarista. Sobre os mecanismos de alcance e de promoção dos direitos, a dignidade da pessoa humana tem de ser vista como fundamento de um direito geral e amplo de igualdade e liberdade, atingível pela instrumentalização de um direito de igual liberdade. ${ }^{16}$

Como macroprincípio, a dignidade é um instrumento de avaliação da dimensão normativa da Constituição, tendo a função de fundamentar a Ordem Jurídica dos Direitos Humanos, sendo, inclusive, fonte de observação e integração. ${ }^{17}$ Desse modo, quando os Tribunais, de um modo geral, constroem a doutrina da dignidade como fundamento judicial, devem estar atentos à Ordem Constitucional e ao processo de formação da jurisprudência - elemento que edifica conceitos reprodutíveis e que deve ser encarado como tecido fino, de cuja construção somente podem participar vetores caros ao Direito. ${ }^{18}$

Ao buscar elementos-padrão que sirvam de fundamento aos direitos humanos, é necessário que as Instituições ${ }^{19}$ busquem superar a vagueza da definição do conceito, a volatilidade ou variabilidade de tal categoria de direitos e a heterogeneidade e a antinomia entre os direitos invocados pelas mesmas pessoas - tão perceptíveis quando estão em discussão os direitos sociais.

Com efeito, a dignidade humana não deve ser utilizada como forma de repressão a um grupo minoritário (ainda que radical) ou como fundamento para cercear a liberdade de expressão, como ocorre em alguns movimentos sociais domésticos e internacionais. $\mathrm{O}$ uso indefinido da dignidade como argumento de reforço do discurso do ódio pode conduzir à banalização do princípio e à sua ruína enquanto pilar para os Direitos Humanos.

A teor dos usos extremistas ou indevidos da dignidade fundamentando Direitos Humanos, quando se buscam definições para "dignidade humana" ou "igual reconhecimento e respeito", pode-se recorrer às várias definições legais ou apenas pensar na Gestapo Alemã torturando um oponente político do Holocausto $^{20}$ em nome da "dignidade" de alguns.

Dada a relatividade temporal e física a que se sujeitam os Direitos $\mathrm{Hu}$ manos, o estabelecimento de elementos padronizados - os quais, em tese, se repetiriam em cada situação concreta e em cada conceito de direito humano de cada sociedade - não aponta para uma uniformidade ou para a universalização do conceito.

Por outro lado, a fundamentação, o pavimento sobre o qual se desenvolvem os Direitos Humanos pode ser composto de uma amálgama de macroprincípios que carregam consigo a dignidade humana. 


\subsection{A DIVERSIDADE DOS MEIOS E DISCURSOS DE INVOCAÇÃO DA DIGNIDADE COMO FUNDAMENTO DOS DIREITOS HUMANOS}

$\mathrm{Na}$ investigação dos fundamentos imutáveis dos direitos do homem, repousa a asseverada crítica de que essa "ilusão" já não é mais possível hoje e toda busca do fundamento absoluto somente pode ser infundada. ${ }^{21}$ É preciso verificar como a dignidade pode integrar a composição basilar dos direitos fundamentais em um dado momento histórico e, em outro, por mais absurdo que possa parecer, seja a dignidade invocada como meio de repelir aqueles direitos. ${ }^{22}$

É que os Direitos Humanos, além de relativos e oscilantes em modalidades e em âmbito de aplicação, apresentam, também, um comportamento crescente, desde que sejam preenchidos os requisitos democráticos básicos e sejam aceitos os meios de enforcement domésticos e internacionais mais comuns.

Quanto mais direitos são concedidos a um indivíduo, maior será sua propensão a exigir mais e mais direitos - especialmente direitos humanos. Isso se deve ao fato de que o indivíduo, ao perceber o "aumento" (e não a mera inflação) de sua dignidade, sente-se mais confortável para requerer maiores liberdades, como se houvesse uma tendência ou efeito cascata/dominó. ${ }^{23}$

Sobre o sistema expansionista que adotam os Direitos Humanos - em razão de maiores avanços sociais, por exemplo - parece assentar uma curiosa harmonia entre polos opostos de poder. É que a bandeira dos Direitos Humanos (ou de sua expansão) é deveras conveniente a reforçar os variados discursos, por meio da formação de uma ideologia dominante. ${ }^{24}$

A difusão dos Direitos Humanos e as exigências no tocante a sua promoção permitem verificar que o exercício continuado da democracia política admite, paulatinamente, a ampliação do gozo dos Direitos Humanos, criando um círculo virtuoso no qual a cultura política também se modificaria, ${ }^{25}$ especialmente porque os referidos direitos integram uma plataforma ou um palanque para a obtenção de mais direitos. ${ }^{26}$

A dignidade é invocada como fundamentação de Direitos Humanos quando, por exemplo, tal categoria de direitos é maculada, ferida ou ignorada, eis que os direitos são manifestações das transformações da sociedade moderna. ${ }^{27}$ Nessa situação, os Estados - provedores de liberdade e autonomia (componentes da dignidade) -, por não desempenharem o papel estabilizador de maneira eficiente, recaem em crises institucionais de legitimidade e de política nacional. É que os Direitos Humanos proveem um padrão moral da legitimidade política nacional e também emergem como um "padrão político internacional de legitimidade." 28

Pelo que se pode depreender que a violação de Direitos Humanos, por carência do provimento de elementos que lhes sejam fundantes - como a dignidade, em exemplo concreto - compromete a legitimidade das instituições nacionais e internacionais. $\mathrm{O}$ aludido comprometimento reforça o discurso dos 
excluídos e dá azo aos movimentos de reforma social e enseja diversas manifestações, o que faz da crise um instrumento de transformação. ${ }^{29}$

Portanto, a jurisprudência de casos, construída pelo STF, quando pertinente ao emprego da dignidade como mecanismo de promoção ou proteção de Direitos Humanos, deve construir uma estrutura sólida, de modo que seja válida a formar um conceito útil para a interpretação de normas atinentes àqueles direitos (humanos).

\subsection{A FRAGILIDADE DA DIGNIDADE COMO ÚNICO FUNDAMENTO}

Há oposição, na realidade acadêmica, para a dignidade servir de único fundamento aos Direitos Humanos. A referida corrente, apesar de considerar a dignidade inerente ao ser humano, refuta, e com razão, a fundação dos Direitos Humanos unicamente pela dignidade. ${ }^{30}$

Compreende-se que a dignidade não pode funcionar como único esteio para os Direitos Humanos. Inclusive, se assim o fosse, de um lado, sua quebra seria facilitada e, de outro ângulo, o surgimento de valores ou vontades humanas travestidas de "direitos" seriam facilmente justificados como ensejadores ou promotores da dignidade e, sob tal égide, deveriam ser tutelados pelo Estado.

O objetivo primordial dos Direitos Humanos, enquanto processos de conquista e ampliação do campo de desenvolvimento da vida humana, é o de assegurar (ou promover) a vida com dignidade, como o é feito na positivação constitucional brasileira, e a promoção da vida com dignidade pressupõe um corolário de Direitos Humanos que sejam pautados em processos igualitários na aquisição e no acesso aos bens e aos valores humanos.

A Constituição Cidadã, ao prever a dignidade como fundamento da República, erigiu o macroprincípio à vertente de interpretação dos direitos fundamentais - previstos no art. $5^{\circ}$ da CF e em tantas outras passagens -, que consubstanciam a aplicação doméstica dos Direitos Humanos.

Anote-se que a Constituição, ao gravar a dignidade humana como cláusula pétrea, ${ }^{31}$ pretende conferir máxima efetividade aos direitos humanos fundamentais, por situá-la em lugar de destaque no ordenamento jurídico-constitucional. Referida constatação reforça a reflexão que defende o alto preço do preceito 'dignidade' e corrobora a tese de que o emprego do instituto pelos tribunais deve ser reservado a construções jurídicas de relevo na estrutura social.

Como o titular da dignidade é o sujeito que ostenta Direitos Humanos, resta ao Estado prover-lhe condições para o desenvolvimento desses direitos e repelir injustas agressões. Isso se dá, em larga medida, porque o atributo "dignidade" está desvencilhado das circunstâncias pessoais de seu portador. ${ }^{32}$

O reconhecimento do direito do outro como resultante de sua dignidade advém da noção de igualdade, de sorte que, características de índole étnica, de raça, de condição social, ou gênero, não possuem o condão de repelir a funda- 
mentação do direito daqueles humanos em sua dignidade e em outros valores e macroprincípios, por exemplo, o da isonomia.

\section{A DEFESA DOS DIREITOS HUMANOS POR MEIO DA DIGNIDADE EM DECISÕEES DO STF E DA CIDH}

Diariamente, as Decisões do Supremo Tribunal se tornam manchetes dos principais jornais brasileiros, e nos mais variados temas, como política, economia, cultura, sexualidade, etc. A interpretação e jurisdição constitucionais têm verificado um elo político fundamental entre indivíduos e Estados, traçado pelos Direitos Humanos, em vista do que o Supremo, em suas decisões multifacetadas, tem-se tornado objeto de diversos estudos.

É surpreendente a atenção que os não especialistas voltam ao STF, e é instigante o crescimento do número de brasileiros que vai verificando, nas decisões do Tribunal, questões cruciais de natureza política, moral ou econômica, a partir de uma linguagem de compreensão difícil..$^{33} \mathrm{~A}$ proeminência do Tribunal no cenário político do país é fato notório, e suas orientações do emprego da dignidade como mecanismo de justificação dos Direitos Humanos têm influência ímpar nas decisões judiciais, políticas e econômicas do país.

\subsection{DA FORÇA DA CONSTRUÇÃO JURISPRUDENCIAL, OU DO PORQUÊ DE SE ANALISAR O ARCABOUÇO DAS DECISÕES JUDICIAIS}

Ao ocupar destacada posição no campo da definição e do emprego da dignidade como fundamento para os Direitos Humanos, a Corte Constitucional do Brasil deve oferecer socorro às questões que lhe são apresentadas e, naturalmente - dada a universalidade e transnacionalidade daqueles direitos - elaborar decisões consentâneas com as decisões da CIDH.

No entanto, o conceito operacional ${ }^{34}$ tem aparições usuais carregadas de uma abrangência tão marcante que o desenho que se esboça é de efemerização do instituto.

O fortalecimento da autoridade da Corte Suprema (e dos Tribunais em geral) parece ter sido uma consequência do descrédito da população no Congresso Nacional e nas arenas políticas em planos regionais, ${ }^{35}$ enquanto legítimos garantidores dos Direitos Humanos, e na expansão do sistema econômico de mercado. Nesse contexto, para os detentores de poder econômico (e de influência política), os tribunais constituiriam um meio mais confiável para garantir a segurança jurídica, estabilidade e previsibilidade do que legisladores democráticos, usualmente premidos por demandas populistas. ${ }^{36}$

Entrementes, o resultado da apreciação de certos casos pelo STF, quando atinentes à utilização da dignidade como fundamento e mecanismo de aplicação ou garantia de Direitos Humanos, deve conduzir à conceituação da relação e à 
sedimentação do princípio enquanto matiz válido de interpretação de normas atinentes àqueles direitos (humanos).

Especialmente no contexto de mudança cultural e da exigência popular de repressão aos abusos e às violações, o Governo (pelas Instituições que, em um cenário natural, elaboram políticas públicas) ou as Instituições preexistentes, mas não elaboradoras voluntárias de políticas públicas, como o STF, devem preconizar a garantia e a promoção dos Direitos Humanos. Tal fato decorre da crescente pressão das organizações internas e internacionais para que se promovam e cumpram Direitos Humanos. ${ }^{37} \mathrm{Na}$ mesma via, correm as decisões da CIDH, que tutelam os Direitos Humanos em âmbito Americano.

Por isso, é importante apresentar os julgados daqueles Tribunais, onde se encontram razões ou justificativas para a invocação da dignidade como plano de sustentação dos direitos de liberdade, de cidadania, de autonomia, de qualidade de vida, enfim, de Direitos Humanos.

A construção do conceito de dignidade da pessoa humana na CIDH e em outros tribunais internacionais deriva de certa forma dos conceitos criados pela Declaração Universal dos Direitos Humanos. O texto se inicia com a evocação do princípio da dignidade da pessoa humana logo no primeiro parágrafo do preâmbulo, ${ }^{38} \mathrm{e}$, da sua mera leitura, percebe-se que a dignidade não é fundacional dos Direitos Humanos, mas reconhecida em paralelo com o direito à igualdade. Dignidade e igualdade fundamentam liberdade, justiça e paz. Em seguida, a Declaração coloca os demais direitos como requisitos (e não apenas como fundamento) para que haja dignidade. Desse modo, a fim de que exista dignidade, é preciso segurança social, cooperação internacional, respeito aos direitos econômicos, sociais e culturais, ${ }^{39}$ além de trabalho com salário suficiente para manter uma "existência digna." ${ }^{40}$ De qualquer modo, houve o êxito de determinar o repúdio ao sexismo, antissemitismo, racismo.

A Convenção Americana de Direitos Humanos garante o direito à vida. A Corte IDH precisa o conceito ao falar em vida digna. A dignidade é condição para o exercício do direito à vida. $O$ direito à vida está no art. $4^{\circ}$ e compreende a proteção contra a morte. Nesse contexto, considera-se a vida desde a concepção. $\mathrm{O}$ início da vida na concepção é questionado na Corte IDH, sobretudo no tocante ao descarte de embriões in vitro. A partir da interpretação evolutiva do texto, que claramente coloca o início da vida na concepção, discutiu-se a legalidade da legislação da Costa Rica que previa a existência da proteção da vida na concepção extrauterina e, portanto, a proibição de descarte e uso de embriões. Logo, acabava-se por proibir a fertilização in vitro.

$\mathrm{Na}$ visão da Corte, dizer o início da vida significaria violar o direito de liberdade religiosa, porque o próprio início da vida varia conforme a religião. $\mathrm{O}$ artifício argumentativo viabilizou a interpretação contra o texto literal do tratado. O momento do início da vida foi finalmente concluído pela implantação do óvulo. A Corte usa ainda como argumento que uma interpretação diferente 
significaria o uso do aborto ilegal, inseguro e seria sim uma violação ao direito à vida. Provavelmente teria sido melhor usar da margem nacional de apreciação, deixando a cada Estado regular o tema, conforme sua cultura e especificidade ou então ter ponderado melhor os fundamentos da sentença. ${ }^{41}$

De outro, na jurisprudência da Corte, não se proíbe a pena de morte, que fica restrita aos delitos mais graves e quando houver condenação judicial. Determina-se o não reestabelecimento da pena de morte nos países em que houver sido abolida; a inexistência de pena de morte para crimes políticos, para os menores de dezoito e para maiores de setenta anos.

A pena de morte exige a individualização da pena e sua punição na medida da sua culpabilidade e participação. ${ }^{42} \mathrm{~A}$ ideia, já exposta em diferentes casos, é a redução gradual da pena de morte até o desaparecimento. A interpretação contínua do princípio pro persona e o não retrocesso previsto no art. $4^{\circ}$ da CADH garantem a evolução gradual em direção a sua extinção. A questão se colocou em Barbados, no tocante às competências do Conselho Privado de Barbados, que exercia o poder de aconselhamento ao Governador sobre a clemência dos condenados à morte. ${ }^{43}$

No tocante aos presos, por exemplo, a Corte IDH assente que o Estado tem o dever de zelar pelo desenvolvimento de vida digna, de todos aqueles sob sua jurisdição, inclusive presos ${ }^{44}$ Os detentos não devem ser submetidos a níveis "inevitáveis de sofrimento intrínseco à detenção", assegurando-se a sua saúde e o seu bem-estar de forma adequada, bem como assistência médica. ${ }^{45}$

No contexto europeu, várias decisões confirmam a responsabilidade do Estado quando está intervindo em outros países, ainda que a intervenção não seja reconhecida pela comunidade internacional. A Corte Europeia de Direitos Humanos considerou em diferentes ocasiões os Estados europeus agindo em nome da Organização das Nações Unidas como responsáveis por ações e omissões que geraram violações aos Direitos Humanos. ${ }^{46}$

O mesmo conceito se desenvolve em vários elementos, dentro da ideia de projeto de vida, vida digna como direito de conhecer sua história (comissões da verdade, leis de anistia), morte digna, falta de dignidade na espera pelo corredor da morte, individualidade, liberdade e propriedade, com forte desenvolvimento argumentativo.

\subsection{O DISCURSO JURISPRUDENCIAL NA TENTATIVA DE FORMATAR UM CONCEITO OPERACIONAL DE DIGNIDADE: JULGADOS DISTIN- TOS COM FUNDAMENTAÇÃO ABRANGENTE}

O STF emprega a dignidade para repelir qualquer agressão ao ser humano, a fim de evitar prisões, torturas, maus-tratos e qualquer outra forma de violação da autonomia individual inclusive em âmbito processual. Tal orientação parece emergir de uma tentativa de escapar de eventuais submissões de seus julgados à Corte Internacional por meio da expansão da tutela doméstica (prestada pela Corte Constitucional). 
Nesse diapasão, é oportuno reforçar o caráter plurivalente dos Direitos Humanos, esteados na dignidade, e frisar a lição de que, em uma visão abrangente, os Direitos Humanos devem ser considerados como a colocação em prática de disposições críticas em relação ao conjunto de posições desiguais que as pessoas e os grupos ocupam. ${ }^{47}$

Passa-se, nesse ponto, a apresentar o comportamento - por vezes volátil - da jurisprudência, enquanto discurso construído pelo STF, a fim de verificar como a conceituação da dignidade pode representar um argumento na defesa de Direitos Humanos pelo Tribunal.

A Corte constrói bases para os Direitos Humanos - suas garantias e seus meios de exercício - com o emprego da dignidade, por exemplo, ao firmar que a duração prolongada e irrazoável da prisão cautelar de uma pessoa ofende o postulado da dignidade da pessoa humana. ${ }^{48} \mathrm{O}$ argumento central do Tribunal é a altivez do princípio veiculado no artigo $1^{\circ}$, inciso III, da $\mathrm{CF} / 88,{ }^{49}$ como valor-fonte conformador de todo o ordenamento constitucional vigente no país.

No mesmo sentido, de linha exemplificativa, pode-se extrair pequeno trecho do Voto condutor da Arguição de Descumprimento de Preceito Fundamental versante sobre os presídios domésticos - em que, apenas no julgamento das medidas cautelares pleiteadas, já foi construída uma lição de direitos fundamentais. A Corte esposou uma argumentação interessante, no que concerne à viabilidade da dignidade como fundamento. $\mathrm{Na}$ hipótese, entendendo-se a relevância da impopular pauta dos Direitos Humanos dos presidiários (um grupo estigmatizado), buscou-se a dignidade para deferir algumas das medidas cautelares, consistentes na liberação das verbas do Fundo Penitenciário Nacional, e a realização de audiências de custódia. ${ }^{50}$

O caso em verte, no tocante ao cenário caótico dos presídios brasileiros e da consequente violação dos Direitos Humanos dos presidiários, autoriza pelos mais diversos argumentos - devidamente esposados no julgamento das cautelares - a ampla invocação da dignidade com fundamento para a decisão, quando presentes elementos concretos, construídos no próprio texto, para a prática. Apenas para ilustrar, veja-se que a expressão 'dignidade' aparece no inteiro teor do Acórdão mais de 90 (noventa) vezes (no julgamento das medidas cautelares, uma vez que ainda não se julgou o mérito da questão), - a denotar a preocupação do Tribunal com o preceito fundamental (e fundante).

Com a mesma orientação julga a Corte IDH, ao assentar que o isolamento prolongado e a falta de comunicação de um preso representam, por si mesmos, formas de tratamento cruel e desumano, lesivas à liberdade psíquica e moral da pessoa e do direito de todo detido ao respeito devido à dignidade inerente ao ser humano. ${ }^{51}$

A inteligência das cortes é conferir a máxima efetividade à proteção da pessoa humana contra tratamentos desumanos ou degradantes, por meio da invocação da dignidade como fundamento. Quando se priva uma pessoa da 
vida, também é infringida sua integridade pessoal, de modo que toda pessoa privada de liberdade deve ser tratada com o respeito devido à dignidade inerente ao ser humano. ${ }^{52}$

Assim, naqueles casos, a veiculação do argumento é amparada pelo elevado valor das garantias envolvidas e protegidas pelos setores. À mercê da carência de ação do Poder Público, o Poder Judiciário tem assumido o papel de orientador da ação pública coordenada e lavrado decisões, em que pese acoimadas de ativistas, mas que garantem efetivamente, e em casos concretos, Direitos Humanos.

Exemplo processual interessante foi a Ação Direta (ADI) que objetivou a declaração de inconstitucionalidade de dispositivo da Constituição do estado de Santa Catarina que previa a chamada "defensoria pública dativa", empregada pelo estado com o fito de burlar a obrigatoriedade da criação da Defensoria Pública Estadual. ${ }^{53}$ Ao apreciar o caso, o STF declarou a inconstitucionalidade do dispositivo da Constituição estadual por afronta à dignidade do ser humano, que lhe garante direitos de ampla defesa, livre acesso à justiça, "defensor natural", enfim, Direitos Humanos.

A conceituação daquele Tribunal é de que o direito à Assistência Judiciária gratuita, como caráter de direito inerente à pessoa humana, pauta-se na dignidade. A dignidade é um "valor-fonte" de todo o ordenamento constitucional e, portanto, deve ser invocada na defesa de qualquer direito humano em virtude da posição central e da essencialidade do instituto.

No Brasil, em virtude do conceito produzido jurisprudencialmente pelo Tribunal, verifica-se que o "direito sexual" pode ser fundamentado na dignidade. Tal foi o caso do reconhecimento do instituto da união homoafetiva, ${ }^{54}$ em que se assentou que a busca da felicidade se posiciona como direito do ser humano no exercício de sua dignidade.

O reconhecimento do direito à orientação sexual prepara terreno para o exercício do "direito à autoestima", e toda forma de preconceito deve ser banida, em virtude do "direito à busca da felicidade" com a proibição do preconceito para a proclamação do direito à liberdade sexual.

A inclusão, no corpo social, do direito à escolha de orientação sexual particulariza-se, para o STF, como emanação direta do princípio da dignidade. Como direito à autoestima, situado no mais elevado ponto da consciência do indivíduo, a dignidade fundamenta o direito humano "da busca da felicidade", seja ela na área afetiva, sexual, seja em qualquer manifestação da vida privada. Mais uma vez, a Suprema Corte cuidou de abrir o corolário da dignidade para dela emergirem Direitos Humanos, o que reforça a tese de fundamento.

No entanto, as invocações da dignidade pelo STF nem sempre se preocupam com a altivez do princípio e podem, consequentemente, representar momentos de inflação do conceito. A Ação Direta $^{55}$ que tratou do regime de 
preferências subjetivas para o percebimento de precatórios, estatuído pela EC $n^{\circ} 62 / 2009$, de cunho tributário e processual, é outro julgado em que se empregou a dignidade para fundar um processo de aquisição de Direitos Humanos no Brasil. A dignidade é razão de preferir idosos e portadores de deficiência no pagamento das verbas, porque o pagamento prioritário promove, de modo razoável, a dignidade da pessoa humana.

Assim, Direitos Humanos de caráter econômico podem ser ranqueados em virtude de condições pessoais de seu detentor porque tal escalonamento, na inteligência do STF, promove a dignidade da pessoa humana.

Na seara eleitoral, é de se anotar a ADI que questionava os critérios de doações para partidos políticos, por pessoas jurídicas e naturais e para o uso de recursos próprios pelos candidatos, que foi julgada parcialmente procedente, a fim de coibir doações por pessoas jurídicas a partidos políticos. No caso, a inconstitucionalidade foi fundamentada em diversos preceitos ${ }^{56} \mathrm{e}$, curiosamente, exsurgiu, na argumentação para retificar os limites previstos na legislação, a expressão da dignidade, empregada em uma "postura mais ativa" do Supremo Tribunal Federal. ${ }^{57}$ No julgado, a dignidade emerge em excerto de citação do Acórdão: "em matérias como a presente não se reduz jamais ao campo estrito da hermenêutica constitucional, exsurgindo, antes de tudo, como autêntica questão de modelagem institucional no Estado Democrático brasileiro." 58

Outra passagem que segue o ímpeto de abrangência do Tribunal foi a garantia do levantamento dos valores recolhidos a título de FGTS ${ }^{59}$ aos empregados admitidos para desempenhar funções administrativas no poder público sem a realização de concurso e desligados até 28 de julho de $2001 .^{60}$ É que, para a Corte, mesmo que 'contratados' a título precário e com incorreção procedimental, o caráter social do fundo evidencia uma ponderada escolha legislativa, que cuida de aperfeiçoar a aplicação e a eficácia do princípio da dignidade da pessoa humana. De modo que a liberação para levantamento dos importes deve ser assegurada também àquele contratado por instrumento eivado da nulidade consistente na ausência de submissão do trabalhador a prévio certame público. As passagens abaixo ilustram a ideia:

O caráter social do FGTS, enquanto integrante de política pública de notáveis dimensões comunitárias e sociais, evidencia quão ponderada foi a escolha legislativa, para aperfeiçoar a eficácia dos princípios da dignidade da pessoa humana e valorização do trabalho e do emprego, ao assegurá-lo também no contrato de trabalho nulo pela ausência de submissão do trabalhador a certame público. [...] Os dispositivos acoimados de inconstitucionais na presente $\mathrm{ADI}$ visam apenas a diminuir, ainda que minimamente, o prejuízo sofrido pelo trabalhador que entrega a sua força de trabalho de boa-fé à Administração Pública -, como poderia fazê-lo a qualquer outro empregador-, mas resta privado dos direitos trabalhistas basilares consagrados no art. $7^{\circ}$ da Magna Carta, fundamentais à dignidade da pessoa humana. 
No sistema jurídico brasileiro, há normas expressas ${ }^{61}$ proibindo condutas que violem a dignidade e, não raro, disciplinam como aplicar o preceito, o que significa a densificação do instituto por incorporação ou por produção normativa direta do constituinte, ou do legislador. Em tais casos, intuitivamente, o intérprete aplicará a regra positivada, sem a necessidade da busca hermenêutica pelo valor ou princípio mais elevado. ${ }^{62}$

Ocorre que a atividade de recorrência ao princípio da dignidade em tantas atividades usualmente ordinárias pelo STF não é o preenchimento de lacunas normativas, mas a retórica via da facilidade da argumentação principiológica.

Ora, frise-se que a dignidade está em jogo quando é negada ao indivíduo a sua capacidade de autodeterminação em esferas básicas de sobrevivência, mas não em qualquer violação ou aparente desrespeito a seus valores inerentes.

A ideia subjacente é que o próprio conceito de dignidade da pessoa humana pode deslegitimar-se quando for utilizado como recurso argumentativo em temas que tem relação muito indireta com esse conceito, como o Direito Tributário, por exemplo. Se todos e quaisquer temas forem enquadrados como "dignidade da pessoa humana", o resultado pode ser negativo para a própria seriedade da construção do conceito de dignidade da pessoa humana.

Violações à autonomia do indivíduo que tenham o condão de prejudicar sua autonomia, liberdade e seu projeto de vida é que se apresentam violação à dignidade. Assim se tece um conceito valoroso e resguardado da dignidade fundamentadora. ${ }^{63}$

Com tal alargamento conceitual, o Tribunal tem materializado a dignidade num curinga jurídico, o que contribui para seu uso como plataforma de Direitos Humanos. $\mathrm{O}$ que o Tribunal empreende quando recorre à dignidade para fundamentar as mais diversas (e até antagônicas) situações é uma constitucionalização simbólica ${ }^{64}$ do conceito operacional, para validar questões distantes do próprio conceito.

É preciso atenção da Corte para evitar as aplicações exageradas do conceito operacional. ${ }^{65} \mathrm{~A}$ invocação de princípios se apresenta como uma panaceia que soluciona todos os conflitos de cunho jurídico-constitucional, sabendo o Tribunal que a popularização desta invocação empresta um tom de respeitabilidade a qualquer tese, mesmo as mais absurdas. ${ }^{66}$

Como já registrado, não é um aparente desrespeito, por vezes, de resvalada importância, a valores tangenciais aos Direitos Humanos que autoriza o emprego da dignidade para, no amplamente debatido exemplo, a declaração de inconstitucionalidade da lei do estado do Rio de Janeiro que regulamentava exposições e competições entre aves. A promoção de brigas entre aves das raças combatentes no emblemático caso, para o STF, ofende a dignidade humana, ao estimular emoções primitivas e irracionais, porque diminuem o ser humano: ${ }^{67}$ rinha de galos afronta a dignitás. 
Os diversos casos decididos pelo STF revelam inconstância no cuidado com os princípios constitucionais. Cuida-se, muitas vezes, de construções dogmáticas sem o crivo seletivo de uma percepção jurídico-constitucional nacionalizada. ${ }^{68}$ A afirmação dos Direitos Humanos como decorrentes da garantia de dignidade ao ser humano cria espaço de discussão quanto aos mecanismos de segurança e garantia de tais direitos.

Assim, a "novidade" do emprego dos Direitos Humanos como supedâneo digno de decisões judiciais e a grande repercussão que o tema alcança no âmbito jurídico-constitucional e internacional contribuem para a dificuldade de conceituação da categoria, mas, ao mesmo tempo, corroboram o emprego da dignidade como elemento fundante. Tais mecanismos inovadores de garantia dos Direitos Humanos já foram apontados como causas dos problemas de interpretação e fundamentação. ${ }^{69}$

Em que pese a fundamentação dos Direitos Humanos na dignidade, esta está, a priori, excluída de fatos cotidianos ou banais, ${ }^{70}$ a invocação costumeira e consuetudinária do fundamento em relações causais confere reconhecimento popular ao conceito operacional. Isso ocorre porque o uso exacerbado do fundamento "dignidade" contribui para o seu crescente emprego e para a recorrência de sua invocação nas variadas esferas sociais, elucidando uma possível fundamentação abrangente para o emprego da expressão.

De toda sorte, a justa medida no emprego do fundamento, em que pese o favorecimento na expansão das bases dos Direitos Humanos que o emprego recorrente encerra, é medida recomendada. A banalização, por mais resultados positivos que encerre em curto prazo, deve ser comedida, uma vez que o exagero do emprego conduz à perda de valor e a inserção do fundamento na barafunda dos chavões jurídicos.

\section{CONSIDERAÇÕES FINAIS}

Não se pode repelir a dignidade da base de desenvolvimento e da aplicação dos Direitos Humanos. Pelo contrário, a evolução do conceito de dignidade e a sedimentação de sua aceitação prática, em especial na democracia brasileira, podem proporcionar avanços tanto no reconhecimento quanto na aplicação dos Direitos Humanos.

O fulcro que os Direitos Humanos encontram na dignidade contribui para o desenvolvimento da democracia, haja vista a consequente assimilação de que é o Estado que existe em função do ser humano, e não o contrário.

Nesse contexto, o plano sobre o qual se desenvolvem os Direitos Humanos é cravejado de macroprincípios, dentre os quais se destaca a dignidade humana.

A dignidade, como reconhecimento do ser humano pelos semelhantes, é um conceito político e deve ser abrangente o suficiente para fundamentar os Direitos Humanos. Portanto, a dignidade deve ser desenvolvida como conceito e como prática, numa visão política abrangente. 
O elemento fundante "dignidade" está associado, em termos gerais, com as condições que favorecem a vida e o desenvolvimento das virtudes humanas que se consubstanciam em Direito Humanos de cunho político, social, econômico.

Quanto mais direitos são concedidos a um indivíduo, maior será sua propensão a exigir mais e mais direitos humanos. Assim, o fenômeno "cascata" toma força, em larga medida, porque o atributo "dignidade" está desvencilhado das circunstâncias pessoais de seu portador e funda Direitos Humanos, que são universalizáveis.

Ao mesmo tempo, é necessária cautela na invocação da dignidade como fundamento de direitos, especialmente em razão dos malefícios oriundos de aplicações inflacionadas e do uso indevido na justificação do discurso do ódio ou de quaisquer discursos extremistas.

Somente quando a autonomia do indivíduo sofrer ameaças de consideração que tenham o condão de lhe minorar as condições de sobrevivência é que se apresenta uma quebra de dignidade, uma violação de Direitos Humanos.

Todavia, o STF, ao promover a "constitucionalização simbólica" do conceito operacional nos casos analisados, parece empregar a dignidade para repelir qualquer agressão aos Direitos Humanos, fundamentando que a dignidade é um "valor-fonte" de todo o ordenamento constitucional e, assim sendo, deve ser invocada na defesa de qualquer direito humano, dada a posição central e da essencialidade do instituto.

Assim agindo, a Corte encampou a tese de que a dignidade humana, como basilar fundamento dos Direitos Humanos, é um princípio constitucional supremo, erigindo, para tanto, o conceito operacional a um imperativo categórico. ${ }^{71}$

De fato, a Suprema Corte entende que a garantia dos Direitos Humanos é proporcionada pelo fundamento da dignidade quando ocorre (I) a vedação à duração prolongada, abusiva e irrazoável da prisão cautelar de alguém; (II) a obrigatoriedade de instituição de Defensoria Pública; (III) a preferência a idosos e portadores de deficiência no pagamento de precatórios; e (IV) o reconhecimento do direito à orientação sexual como direta emanação do princípio da "dignidade da pessoa humana", por exemplo - ou seja, a amplitude conceitual não permite operacionalizar o conceito.

Por outro lado, com visto, o emprego do fundamento já aparece de forma mais comedida na Corte Interamericana de Direitos Humanos.

Percebe-se, dos casos apresentados, que a invocação consuetudinária do fundamento e da relação de causa e efeito (dignidade/Direitos Humanos) confere reconhecimento popular ao conceito operacional e auxilia a recorrência de sua invocação nas variadas esferas sociais, elucidando uma possível fundamentação abrangente para o emprego da expressão, sobretudo com os argumentos trabalhados pela CIDH. 
No entanto, o emprego exacerbado do fundamento reforça a retórica conducente à banalização do preceito e a sua minoração enquanto base para os direitos, o que requer atenção das Cortes para que sejam evitadas aplicações oportunistas. A dignidade não deve estar incluída em constructos banais ou efêmeros em conteúdo.

O trabalho verificou a posição e o uso do conceito operacional em algumas Decisões do Supremo Tribunal Federal brasileiro e da Corte Interamericana e reforçou a emergência do tema e a importância da fundamentação dos Direitos Humanos na dignidade, de sua difusão e da elucidação das melhores oportunidades de sua invocação - existem relevantes motivos para a conceituação da dignidade como fundamento para aplicação dos Direitos Humanos.

Com isso, amalgamou-se uma argumentação para o emprego da dignidade como um fundamento dos Direitos Humanos, em diversas esferas sociais, com a moderação necessária e requerida pelo amadurecimento político nacional e americano, levando-se em consideração decisões do STF na sua retórica sobre o tema e a inteligência da CIDH.

\section{REFERÊNCIAS}

BARROSO, Luís Roberto. A Dignidade da pessoa humana no Direito Constitucional contemporâneo: natureza jurídica, conteúdos mínimos e critérios de aplicação. Versão provisória para debate público. Mimeografado, dezembro de 2010. BEITZ, C. The Idea of Human Rights. Oxford: OUP, 2009.

BENDA, Ernst. The protection of human dignity (article 1 of the Basic Law). SMU Law Review, United States, v. 53, n. 2, p. 443-454, 2000.

BOBBIO, Norberto. A era dos direitos. São Paulo: Elsevier, 2004.

BONAVIDES, Paulo. Curso de Direito Constitucional. 26. ed. São Paulo: Malheiros, 2011.

BRASIL. Supremo Tribunal Federal. (ADI 4650, Relator(a): Min. LUIZ FUX, Tribunal Pleno, julgado em 17/09/2015. PROCESSO ELETRÔNICO DJe-034 DIVULG 23-02-2016 PUBLIC 24-02-2016).

. Supremo Tribunal Federal. (ADPF 347 Medida Cautelar, Relator(a): Min. MARCO AURÉLIO, Tribunal Pleno, julgado em 09/09/2015. PROCESSO ELETRÔNICO DJe-031 DIVULG 18-02-2016 PUBLIC 19-02-2016).

. Supremo Tribunal Federal. (ADI 3127, Relator(a): Min. TEORI ZAVASCKI, Tribunal Pleno, julgado em 26/03/2015, ACÓRDÃO ELETRÔNICO DJe-153 DIVULG 04-08-2015 PUBLIC 05-08-2015)

. Supremo Tribunal Federal. (HC 98878, Relator(a): Min. CELSO DE

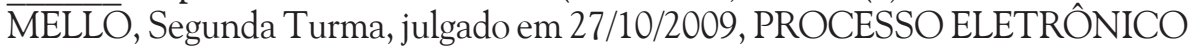
DJe-218 DIVULG 19-11-2009 PUBLIC 20-11-2009). 
. Supremo Tribunal Federal. (ADI 4425, Relator(a): Min. AYRES BRITTO, Relator(a) p/ Acórdão: Min. LUIZ FUX, Tribunal Pleno, julgado em 14/03/2013, PROCESSO ELETRÔNICO DJe-251 DIVULG 18-12-2013 PUBLIC 19-12-2013)

. Supremo Tribunal Federal. (ADI 4277, Relator(a): Min. AYRES BRITTO, Tribunal Pleno, julgado em 05/05/2011, DJe-198 DIVULG 1310-2011 PUBLIC 14-10-2011 EMENT VOL-02607-03 PP-00341 RTJ VOL00219- PP-00212).

. Supremo Tribunal Federal. (ADI 4270, Relator(a): Min. JOAQUIM BARBOSA, Tribunal Pleno, julgado em 14/03/2012, ACÓRDÃO ELETRÔNICO DJe-188 DIVULG 24-09-2012 PUBLIC 25-09-2012).

. Supremo Tribunal Federal. (ADI 1856, Relator (a): Min. CELSO DE

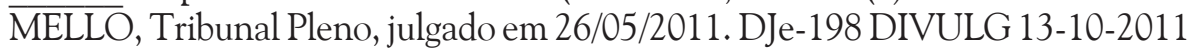
PUBLIC 14-10-2011 EMENT VOL-02607-02 PP-00275 RTJ VOL-00220-01 PP-00018 RT v. 101, n. 915, 2012, p. 379-413).

. Constituição da República Federativa do Brasil de 1988. Disponível em: <https://www.planalto.gov.br/ccivil_03/Constituicao/Constituicao.htm>. CANOTILHO, José J. Gomes; MOREIRA, Vital. Constituição da República Portuguesa anotada. 4. ed. Coimbra: Coimbra Ed., 2007. v. 1.

CARVALHO, José Murilo de. Cidadania no Brasil, o longo caminho. Rio de Janeiro: Civilização Brasileira, 2001.

CORTE EUROPEIA DE DIREITOS HUMANOS. Hassan c. Royaume-Uni - Requête no 29750/09. Arrêt 16 sept. 2014. Ver também Mastromatteo c. Italie [GC], 37703/97, 24 octobre 2002.

CORTE INTERAMERICANA DE DIREITOS HUMANOS [Corte IDH]. Caso Boyce y otros Vs. Barbados. Excepción Preliminar, Fondo, Reparaciones y Costas. Sentencia de 20 de noviembre de 2007.

.Corte IDH. Caso "Instituto de Reeducación del Menor" Vs. Paraguay. Excepciones Preliminares, Fondo, Reparaciones y Costas. Sentencia de 2 de septiembre de 2004.

.Cfr. Caso de los Hermanos Gómez Paquiyauri, supra nota 26, párr. 98; Caso Juan Humberto Sánchez. Sentencia de 7 de junio de 2003.

. Caso "Niños de La Calle" (Villagrán Morales y otros) v. Guatemala. Sentença de 19 noviembre de1999.

. Caso Neira Alegría y otros v. Perú. Sentença. 19 Jan. 1995a.

.Caso Velásquez Rodríguez v. Honduras. Sentença. 29 July 1988.

COSTA NETO, João. Dignidade humana: visão do Tribunal Federal Constitucional Alemão, do STF e do Tribunal Europeu. São Paulo: Saraiva, 2014. 
COSTAS, Douzinas. Human Rights and Empire: the political philosophy of cosmopolitanism. Abingdon: Roudedge, 2007.

DONNELLY, Jack. International Human Rights. [S.1.]: Westview Press, 2013.

. Human Dignity and Human Rights. Denver: University of Denver, 2009. Agenda for Human Rights - 60 Anniversary of the Universal Declaration of Human Rights

DWORKIN, Ronald. Justice for Hedgehogs. Cambridge: Belknap Press of Harvard University Press, 2011.

GUNTHER, Klaus. Human rights and political culture. In: ALSTON, Philip. The EU and Human Rights. Oxford: Oxford University Press, 1999.

HABERMAS, Jürgen. The concept of human dignity and the realistic utopia of human rights. Metaphilosophy, United Kingdom, v. 41, n. 4, p. 464-480, July 2010.

HERRERA FLORES, Joaquín. A (re)invenção dos Direitos Humanos. Florianópolis: Fundação Boiteux, 2009.

HUNT, L. Inventing Human Rights: a history. New York: Norton, 2007.

KANT, Immanuel. Fundamentação da metafísica dos costumes e outros escritos. Tradução de Leopoldo Holzbach. São Paulo: Martin Claret, 2004.

LUTZ, Ellen L.; SIKKINK, Kathryn. International Human Rights Law and Practice in Latin America. International Organization, United Kingdom, v. 54, n. 3, p. 633-659, 2000.

MACKLIN, Ruth. Dignity is a useless concept. British Medical Journal, United Kingdom, v. 327, n. 7429, p. 1419- 1420, 2003.

MAUS, Ingeborg. Judiciário como superego da sociedade. O papel da atividade jurisprudencial na "sociedade órfã". Novos Estudos CEBRAP, São Paulo, n. 58, p. 183-202, nov. 2000.

MONSALVE, Viviana Bohórquez; ROMÁN, Javier Aguirre. As tensões da dignidade humana: conceituação e aplicação no Direito Internacional dos Direitos Humanos. Sur. Revista Internacional de Direitos Humanos, São Paulo, v. 6, n. 11, p. 41-63, 2009.

NEVES, Marcelo. A constitucionalização simbólica. São Paulo: Martins Fontes, 2007.

- Abuso de princípios no Supremo Tribunal Federal. Revista Consultor Jurídico (CONJUR), São Paulo, out. 2012.

PIOVESAN, Flavia. Temas de Direitos Humanos. 7. ed. São Paulo: Saraiva, 2014. 
RAWLS, John. O liberalismo político. Tradução de Dinah de Abreu Azevedo. 2. ed. São Paulo: Ática, 2000.

SARLET, Ingo Wolfgang. Dignidade da pessoa humana e direitos fundamentais. Porto Alegre: Livraria do Advogado, 2011.

STRAUSS, Leo. Direito natural e história. Lisboa: Edições 70, 2009.

VIEIRA, Oscar Vilhena. Supremocracia. Revista Direito GV, São Paulo, v. 4, n. 2, p. 441-464, jul./dez. 2008.

WALDRON, Jeremy. Is dignity the foundation of Human Rights? NYU School of Law, Public Law Research Paper, New York, n. 12-73, Jan. 2013. Available at SSRN: <http://ssrn.com/abstract $=2196074>$.

1 O trabalho não objetiva ponderar sobre o que são direitos humanos para o STF, mas verificar como essa Corte emprega a dignidade para fundamentar o reconhecimento de direitos humanos. Assim, serão analisados julgados em que o Tribunal recorre à dignidade para conferir aplicação prática a direitos humanos.

$2 \S 7^{\circ}$ - Fundado nos princípios da dignidade da pessoa humana e da paternidade responsável, o planejamento familiar é livre decisão do casal, competindo ao Estado propiciar recursos educacionais e científicos para o exercício desse direito, vedada qualquer forma coercitiva por parte de instituições oficiais ou privadas.

3 Art. 227. É dever da família, da sociedade e do Estado assegurar à criança, ao adolescente e ao jovem, com absoluta prioridade, o direito à vida, à saúde, à alimentação, à educação, ao lazer, à profissionalização, à cultura, à dignidade, $[\ldots]$, crueldade e opressão.

4 Art. 230. A família, a sociedade e o Estado têm o dever de amparar as pessoas idosas, assegurando sua participação na comunidade, defendendo sua dignidade e bem-estar e garantindo-lhes o direito à vida.

5 SARLET, Ingo Wolfgang. Dignidade da pessoa humana e direitos fundamentais. Porto Alegre: Livraria do Advogado, 2011. p. 80.

6 HERRERA FLORES, Joaquín. A (re)invenção dos direitos humanos. Florianópolis: Fundação Boiteux, 2009. p. 20.

7 Na defesa do emprego e invocação da dignidade, Luís Roberto Barroso argumenta que, "No Brasil, como regra geral, a invocação da dignidade humana pela jurisprudência tem se dado como mero reforço argumentativo de algum outro fundamento ou como omamento retórico. Existe uma forte razão para que seja assim. É que com o grau de abrangência e de detalhamento da Constituição brasileira, inclusive no seu longo elenco de direitos fundamentais, muitas das situações que em outras jurisdições envolvem a necessidade de utilização do princípio mais abstrato da dignidade humana, entre nós já se encontram previstas em regras específicas de maior densidade jurídica". ("A dignidade da pessoa humana no direito constitucional contemporâneo: natureza jurídica, conteúdos mínimos e critérios de aplicação". Versão provisória para debate público. Mimeografado, dezembro de 2010).

8 Neste texto, tratar-se- á da fundamentação dos direitos humanos pela dignidade funcionando como um conceito operacional.

9 BENDA, Ernst. The protection of human dignity (article 1 of the Basic Law). SMU Law Review, United States, v. 53, n. 2, p. 443-454, 2000.

10 COSTA NETO, João. Dignidade humana: visão do Tribunal Federal Constitucional Alemão, do STF e do Tribunal Europeu. São Paulo: Saraiva, 2014.

11 KANT, Immanuel. Fundamentação da metafísica dos costumes e outros escritos. Tradução de Leopoldo Holzbach. São Paulo: Martin Claret, 2004.

12 PIOVESAN, Flávia. Temas de direitos humanos. 7. ed. São Paulo: Saraiva. 2014.

13 VIEIRA, Oscar Vilhena. Supremocracia. Revista Direito GV, São Paulo, v. 4, n. 2, p. 441-464, jul./ dez. 2008.

14 CANOTILHO, José J. Gomes; MOREIRA, Vital. Constituição da República Portuguesa anotada. 4. ed. Coimbra: Coimbra Ed., 2007. v. 1. 
15 RAWLS, John. O liberalismo político. Tradução de Dinah de Abreu Azevedo. 2. ed. São Paulo: Ática, 2000. p. 185.

16 CANOTILHO; MOREIRA (op. cit., 2007).

17 BONAVIDES, Paulo. Curso de direito constitucional . 26. ed. São Paulo: Malheiros, 2011. p. 105.

18 Nesse sentido, o trabalho de Ingeborg Maus, em "Judiciário como superego da sociedade. O papel da atividade jurisprudencial na "sociedade órfã"” (Novos Estudos CEBRAP, São Paulo, n. 58, p. 183-202, nov. 2000), quando o autor assevera que: "Toda menção a um dos princípios "superiores" ao direito escrito leva - quando a Justiça os invoca - à suspensão das disposições normativas individuais e a se decidir o caso concreto de forma inusitada" (p. 189).

19 Especialmente o Supremo Tribunal Federal, no âmbito doméstico, e a CIDH, no plano americano.

20 GUNTHER, Klaus. Human Rights and Political Culture. In: ALSTON, Philip. The EU and Human Rights. Oxford: Oxford University Press, 1999. p.126: "If you want to know what is meant by "human dignity" or "equal concern and respect" for every human being, you can either look of various kind of legal definitions, or you can think of the German Gestapo torturing a political opponent of the Holocaust of the European Jews."

21 BOBBIO, Norberto. A era dos direitos. São Paulo: Elsevier, 2004. p. 37.

22 STRAUSS, Leo. Direito natural e história. Lisboa: Edições 70, 2009. p.30: "[...] o pensamento humano depende essencialmente de algo que não pode ser antecipado, ou que nunca pode ser um objecto, ou que nunca pode ser dominado pelo sujeito; «ser» no sentido mais elevado do termo não pode significar ou, em todo o caso, não significa necessariamente «ser sempre»."

23 HUNT, L. Inventing human rights: a history. New York: Norton, 2007. p.147: "Rightsissues, therefore, showed a tendency to succeed cascading."

24 COSTAS, Douzinas, op. cit., p. 33: "The rhetoric of human rights seems to have triumphed because it can be adopted by left and right, the north and the south, the state and the pulpit, the minister and the rebel. This is the characteristic that makes them the only ideology in town, the ideology after the end of ideologies, the ideology at the end of history. But this 'broad church' allure of rights is also their weakness."

25 Sobre o tema, destaca-se a obra de José Murilo de Carvalho, intitulada: Cidadania no Brasil, o longo caminho. Rio de Janeiro: Civilização Brasileira, 2001.

26 HERRERA FLORES, Joaquín, op. cit., p. 3.; p. 33.

27 DONNELLY, Jack. Human Dignity and Human Rights. Denver: University of Denver, USA. 2009. Agenda for Human Rights - 60 Anniversary of the Universal Declaration of Human Rights. Research project on human dignity.

28 DONNELLY, Jack. International human rights. [S.1.]: Westview Press, 2013. p. 21: "Human rights thus provide a moral standard of national political legitimacy. They are also emerging as an international political standard of legitimacy. More precisely, the full legitimacy of regimes that grossly and systematically violate human rights is widely seen as compromised".

29 COSTAS, Douzinas. Human rights and empire: the political philosophy of cosmopolitanism. Abingdon: Roudedge, 2007. Roudedge-Cavendish Park Square, Milton Park. Abingdon, OX 14 4RN, UK, p. 105: "The excluded may try to claim political recognition by adopting the existing rules of the game and turning their demands into regional expressions of the established order. This is the case with reformist social movements. There is another scene however in which the excluded group or the banned ideology challenges the social hierarchy. This kind of antagonism or 'dissensus', is not a conflict of interests, opinions or, values; it is a division put in the "common sense": a dispute about what is given, about the frame within which we see something as given".

30 WALDRON, Jeremy. Is Dignity the Foundation of Human Rights? NYU School of Law, Public Law Research Paper, New York, n. 12-73, p. 6, Jan. 2013. Available at SSRN: <http://ssrn.com/ abstract $=2196074>$. "Potential difficulties with the idea that dignity is the foundation of human rights crop up also from another direction. Perhaps the phrase "human dignity" is too vague to be of any foundational use. (...) there is no explicit definition of "human dignity" in any of the charters that invoke it. "Its intrinsic meaning has been left to intuitive understanding...Without a reasonably clear general idea of its meaning, we cannot easily draw specific implications for relevant conduct".

31 Art. $60, \S 4^{\circ}$, IV, da CF/88.

32 BEITZ, C. The idea of human rights. Oxford: OUP, 2009. p. 49: "In summary, human rights are rights possesed by all human beings (at all times and in all places) simply in virtue of their humanity."

33 VIEIRA, Oscar Vilhena, op. cit., p. 3.

34 A fundamentação dos direitos humanos pela dignidade.

35 É o caso das Assembleias Legislativas e das Câmaras Municipais.

36 VIEIRA, Oscar Vilhena, op. cit. 2008. 
37 LUTZ, Ellen L.; SIKKINK, Kathryn. International Human Rights Law and Practice in Latin America. International Organization, United Kingdom, v. 54, n. 3, p. 633-659, 2000. "Domestic human rights organizations demanded that their governments respect human rights and allied with international human rights networks to publicize human rights violations and demand change".

38 "Considerando que o reconhecimento da dignidade inerente a todos os membros da família humana e de seus direitos iguais e inalienáveis é o fundamento da liberdade, da justiça e da paz no mundo".

39 Art. XXII. Todo ser humano, como membro da sociedade, tem direito à segurança social, à realização pelo esforço nacional, pela cooperação internacional e de acordo com a organização e recursos de cada Estado, dos direitos econômicos, sociais e culturais indispensáveis à sua dignidade e ao livre desenvolvimento da sua personalidade.

40 "Art. XXIII, 3. Todo ser humano que trabalha tem direito a uma remuneração justa e satisfatória, que lhe assegure, assim como à sua família, uma existência compatível com a dignidade humana e a que se acrescentarão, se necessário, outros meios de proteção social".

41 Vale citar um trecho da decisão da Corte: "50. Por otra parte, respecto a la controversia de cuándo empieza la vida humana, la Corte considera que se trata de una cuestión valorada de diversas formas desde una perspectiva biológica, médica, ética, moral, filosófica y religiosa, y coincide con tribunales internacionales y nacionales, en el sentido que no existe una definición consensuada sobre el inicio de la vida. Sin embargo, para la Corte es claro que hay concepciones que ven en los óvulos fecundados una vida humana plena. Algunos de estos planteamientos pueden ser asociados a concepciones que le confieren ciertos atributos metafísicos a los embriones. Estas concepciones no pueden justificar que se otorgue prevalencia a cierto tipo de literatura científica al momento de interpretar el alcance del derecho a la vida consagrado en la Convención Americana, pues ello implicaría imponer un tipo de creencias especificas a otras personas que no las comparten".

42 Corte IDH. Caso Boyce y otros Vs. Barbados. Excepción Preliminar, Fondo, Reparaciones y Costas. Sentencia de 20 de noviembre de 2007. Serie C No. 169, Párrafo 50 e 226; Cfr. Caso Hilaire, Constantine y Benjamin y otros Vs. Trinidad y Tobago. Fondo, Reparaciones y Costas. Sentencia de 21 de junio de 2002. Serie C No. 94, párr. 106; Caso Raxcacó Reyes, supra nota 37, párr. 68. Cfr. también Restricciones a la Pena de Muerte (arts. 4.2 y 4.4 Convención Americana sobre Derechos Humanos), supranota 7, párr. 55.

43 Corte IDH. Caso Boyce y otros Vs. Barbados. Excepción Preliminar, Fondo, Reparaciones y Costas. Sentencia de 20 de noviembre de 2007. Serie C No. 169, Párrafo 52

44 Cfr. Caso de los Hermanos Gómez Paquiyauri, supra nota 26, párr. 98; Caso Juan Humberto Sánchez. Sentencia de 7 de junio de 2003. Serie C No. 99, párr. 111; y Caso Bulacio, supra nota 56,párr. 138. En el mismo sentido, cfr. Caso de la Cárcel de Urso Branco, supra nota 54, considerando sexto; y Caso de los Hermanos Gómez Paquiyauri.Medidas Provisionales. Resolución de la Corte Interamericana de Derechos Humanos de 7 de mayo de 2004, considerando décimo tercero. Corte IDH. Caso "Instituto de Reeducación del Menor" Vs. Paraguay. Excepciones Preliminares, Fondo, Reparaciones y Costas. Sentencia de 2 de septiembre de 2004. Serie C No. 112, Párrafo 152

45 Corte IDH. Caso "Instituto de Reeducación del Menor" Vs. Paraguay. Excepciones Preliminares, Fondo, Reparaciones y Costas. Sentencia de 2 de septiembre de 2004. Serie C No. 112, Párrafo 159. Na Europa: Eur. Court H.R. Kudla v. Poland, judgement of 26 october 2000, no. 30210/96, párr. 93-94

46 Neste sentido (CEDH. Hassan c. Royaume-Uni - 29750/09 Arrêt 16.9.2014. Ver também Mastromatteo c. Italie [GC], 37703/97, 24 octobre 2002, Note d'information 46; Maiorano et autres c. Italie, 28634/06, 15 décembre 2009, Note d'information 125; et Choreftakis et Choreftaki c. Grèce, 46846/08, 17 janvier 2012, Note d'information 148) "Em 2014, os oficiais das Nações Unidas no Iraque, em especial da Croácia, receberam reclamações de um homem dizendo que sua família estava ameaçada, mas se omitiram de tomar providências. No dia seguinte, a esposa, advogada no Iraque, reforçou a reclamação. A polícia do Iraque chegou a deter o criminoso na véspera do crime, mas o soltou, porque não fora comunicada das ameaças pelas tropas britânicas. $\mathrm{O}$ resultado foi a morte da advogada, seguida de suicídio do assassino. A Croácia foi condenada por danos morais em 20 mil euros, com base nos art. 2 e 41 da CEDH".

47 HERRERA FLORES, Joaquin, op. cit., p. 96.

48 HC 98878, Relator (a): Min. CELSO DE MELLO, Segunda Turma, julgado em 27/10/2009.

49 Art. $1^{\circ}$ A República Federativa do Brasil, formada pela união indissolúvel dos Estados e dos Municípios e do Distrito Federal, constitui-se em Estado Democrático de Direito e tem como fundamentos: [...] III - a dignidade da pessoa humana.

50 ADPF 347 MC, Relator (a): Min. MARCO AURÉLIO, Tribunal Pleno, julgado em 9/9/2015.

51 Corte IDH, Velásquez Rodríguez vs. Honduras, 1988, par. 156.

52 Corte IDH, Neira Alegría y otros vs. Perú, 1995a, par. 86. 
53 É o que também se extrai do Julgamento da ADI 4270 da Relatoria do Ministro Joaquim Barbosa.

54 ADI 4277, Relator (a): Min. AYRES BRITTO, Tribunal Pleno, julgado em 5/5/2011.

55 ADI 4425 QO, Relator (a): Min. LUIZ FUX, Tribunal Pleno, julgado em 25/3/2015.

56 Tais como os princípios fundamentais democrático, republicano e da igualdade política.

57 (ADI 4650, Relator (a): Min. LUIZ FUX, Tribunal Pleno, julgado em 17/09/2015).

58 ADI 4650, Relator (a): Min. LUIZ FUX, Tribunal Pleno, julgado em 17/09/2015. E continua: “[...] porque a pessoa jurídica tem interesse, o ser humano tem dignidade, e dignidade é que é a base, o ponto fundamental da democracia. E é para se chegar à democracia que nós votamos, que nós fomos votados, que nós podemos eleger. Portanto, faltaria um dado essencial ao humano que é o processo de formação da vontade geral."

59 Fundo de Garantia por Tempo de Serviço.

60 ADI 3127, Relator (a): Min. TEORI ZAVASCKI, Tribunal Pleno, julgado em 26/3/2015. Do julgado extraem-se os seguintes excertos: "O caráter social do FGTS, enquanto integrante de política pública de notáveis dimensões comunitárias e sociais, evidencia quão ponderada foi a escolha legislativa, para aperfeiçoar a eficácia dos princípios da dignidade da pessoa humana e valorização do trabalho e do emprego, ao assegurá-lo também no contrato de trabalho nulo pela ausência de submissão do trabalhador a certame público. [...] Os dispositivos acoimados de inconstitucionais na presente ADI visam apenas a diminuir, ainda que minimamente, o prejuízo sofrido pelo trabalhador que entrega a sua força de trabalho de boa-fé à Administração Pública -, como poderia fazê-lo a qualquer outro empregador-, mas resta privado dos direitos trabalhistas basilares consagrados no art. $7^{\circ}$ da Magna Carta, fundamentais à dignidade da pessoa humana". p. 30.

61 Por exemplo o Estatuto do Idoso (Lei $\mathrm{n}^{\mathrm{o}} 10.741$, de $1^{\mathrm{o}}$ de outubro de 2003), o Estatuto da Igualdade Racial (Lei n ${ }^{\circ} 12.288$, de 20 de julho de 2010) e o Estatuto da Pessoa com Deficiência (Lei n ${ }^{\circ} 13.146$, de 6 de julho de 2015).

62 Como registrado por BARROSO, op. cit., p. 13: "Mas, por exemplo, à falta de uma norma específica que discipline a revista íntima em presídio, será possível extrair da dignidade humana a exigência de que mulheres não sejam revistadas por agentes penitenciários masculinos".63 DWORKIN, Ronald. Justice for Hedgehogs. Cambridge, MA/London: Belknap Press of Harvard University Press, 2011. p. 335: "[...] They (the people) have a right to be treated with attitude that these debates presuppose and reflect - a right to be treated as human being whose dignity fundamentally matters. That more abstract right - the right to an attitude - is the basic human right."

64 NEVES, Marcelo, op. cit., p. 87.

65 Como se verifica, a plasticidade e a maleabilidade do emprego conceitual da dignidade têm evado alguns autores a se posicionar pela inutilidade do preceito. Por exemplo: MACKLIN, Ruth. Dignity is a useless concept. British Medical Journal, United Kingdom, v. 327, n. 7429, p. 1419, 2003.

66 NEVES, op. cit., 2012.

67 O julgamento, que versa sobre a (in) constitucionalidade da Lei n ${ }^{\circ} 2.895 / 98$, do estado do Rio de Janeiro, assentou que "a lei ofende também a dignidade da pessoa humana, porque, na verdade, implica, de certo modo, um estímulo às pulsões mais primitivas e irracionais do ser humano", no esclarecimento do Ministro Cezar Peluso, e também registrou que "está em jogo exatamente esse princípio básico da dignidade da pessoa humana. Quando se trata cruelmente ou de forma degradante um animal, na verdade está se ofendendo o próprio cerne da dignidade humana", no esclarecimento do Ministro Ricardo Lewandowski (ADI 1856, Relator (a): Min. CELSO DE MELLO, Tribunal Pleno, julgado em 26/05/2011).

68 NEVES, op. cit., 2012.

69 BEITZ, C. The idea of human rights. Oxford: OUP, 2009. p. 44: "These features together emphasize the novelty of the practice of human rights. Reflection about them points towards several problems of interpretation an justification."

70 DWORKIN, op.cit., p. 366.

71 HABERMAS, Jürgen. The concept of human dignity and the realistic utopia of human rights. Metaphilosophy, United Kingdom, v. 41, n. 4, p. 464-480, July 2010. 


\title{
A CONCEPTUAL ANALYSIS OF DIGNITY AS THE FOUNDATION OF HUMAN RIGHTS AND ITS USE AND MENTION IN DECISIONS OF THE SUPREME COURT AND THE IACHR
}

\begin{abstract}
The principle of human dignity has recurrently been raised as the foundation of human rights in institutions in democratic societies, such as the Brazilian Federal Supreme Court (STF) and the Inter-American Court of Human Rights (IACHR). To evaluate how dignity can justify the application of human rights, by presenting some decisions by the IACHR, as it is done in the present article, helps to weave a comprehensive foundation in order to enhance the use of the term in various social spheres. Thus, through a theoretical construction of the operational concept of "dignity as a foundation for human rights" and by analyzing decisions on human rights emanating from those courts, the article verifies the validity and efficacy of the use of such basis. There is still ample breeding ground for perfecting concepts and for the definition of paradigms regarding the use of said argument.
\end{abstract}

Keywords: Dignity. Foundation. Human Rights. Brazilian Supreme Court. IACHR.

Submetido: 26 ago. 2016

Aprovado: 28 set. 2016 